\title{
Cost of human immunodeficiency virus infection in Italy, 2007-2009: effective and expensive, are the new drugs worthwhile?
}

This article was published in the following Dove Press journal:

ClinicoEconomics and Outcomes Research

4 September 2012

Number of times this article has been viewed

\section{Giuliano Rizzardini' \\ Umberto Restelli ${ }^{2}$ \\ Paolo Bonfanti ${ }^{3}$ \\ Emanuele Porazzi \\ Elena Ricci' \\ Emanuela Foglia ${ }^{2}$ \\ Laura Carenzi' \\ Davide Croce ${ }^{2}$}

'First Infectious Diseases Department, "Luigi Sacco" Hospital, Milan; ${ }^{2}$ Centre for Research on Health Economics, Social, and Health Care Management, Università Carlo Cattaneo,

Castellanza; ${ }^{3}$ nfectious Diseases Department, "Alessandro Manzoni” Hospital, Lecco, Italy
Correspondence: Giuliano Rizzardini I Department of Infectious Diseases, Luigi Sacco Hospital, via GB Grassi 74, 20157 Milan, Italy

Tel +39239042452

Fax +39234902568

Email rizzardini.giuliano@hsacco.it
Background: In recent years, the increased efficacy and effectiveness of antiretroviral treatment has led to longer survival of patients infected with human immunodeficiency virus (HIV), but has also raised the question of what happens to consumption of resources. Early highly active antiretroviral treatment (HAART), management of hepatitis $\mathrm{C}$ virus (HCV) coinfection, and expensive newly marketed drugs may affect the economic sustainability of treatment from the point of view of the National Healthcare Services. The present study aimed to provide information on the economic burden of HIV-positive patients resident in the Lombardy region using a three-year time horizon.

Methods: This was a retrospective, observational, budget impact study, based on information collected for the period 2007-2009, including hospitalizations, outpatient services, and HAART and non-HAART drug utilization. Patients with confirmed HIV infection, aged $\geq 18$ years, resident in the Lombardy region, and followed at the "L Sacco" Hospital in Milan from 2007 to 2009 were eligible.

Results: A total of 483 patients (mean age 44.1 years) were included in the study. The mean CD4+ cell count increased over the study period from $462 \pm 242 \mathrm{cells} / \mathrm{mm}^{3}$ in 2007 , to $513 \pm 267$ cells $/ \mathrm{mm}^{3}$ in 2008 , to $547 \pm 262$ cells $/ \mathrm{mm}^{3}$ in 2009 . In total, 162 subjects $(33.5 \%)$ were coinfected with HCV. Hospitalizations and HAART costs increased from 2007 to 2009, whereas outpatient visits and non-HAART drug costs decreased slightly over time. The total cost increase was also significant when limiting the analysis to experienced patients, HCV-negative patients, and experienced HCV-negative patients.

Conclusion: CD4+ cell count, a major predictor of costs, increased over the study period. However, immunological improvement was achieved by greater expense in the short term. Whether this may be compensated by a long-term decrease in opportunistic infections and in the costs of management of HIV-related events is an area still to be investigated.

Keywords: health care costs, human immunodeficiency virus infection, risk factors, retrospective study

\section{Introduction}

People suffering from chronic and debilitating diseases are now living longer in developed countries around the world. The resulting economic burden is of concern to health care providers, who are increasingly focusing their attention on the costs of treatment and on the appropriateness of care delivered to patients. The predicted survival years continue to increase for patients diagnosed with human immunodeficiency virus (HIV). ${ }^{1}$ In addition, over 3 million life-years have been saved due to advances made in the treatment of HIV infection. ${ }^{2}$ These changes show the positive 
effects of increasing efficacy and effectiveness, but they also raise the question of what happens to consumption of resources.

From the point of view of the National Healthcare Service, which is now experiencing difficulties in terms of economic sustainability, earlier administration of highly active antiretroviral treatment (HAART), management of hepatitis $\mathrm{C}$ virus (HCV) coinfection, and introduction of expensive new drugs are three factors that may have a significant economic impact.

Italian, ${ }^{3}$ European, ${ }^{4}$ and international guidelines ${ }^{5}$ advise the treatment of HIV-infected patients with a CD4+ cell count $\leq 500$ copies $/ \mathrm{mL}$. However, this leads to a general increase in the number of patients receiving treatment, and, consequently, to an overall increase in health care expenditure. This may not be sustainable for most national health care services, in particular universalistic ones such as Italy, which is already experiencing a reduction in national health care funding. ${ }^{6}$ However, no published literature is available regarding this impact, although the National Healthcare Service is now beginning to ask its health care professionals to consider economic efficiency principles, as has already been done in Germany. ${ }^{7}$

The Italian National Healthcare Service is financed and organized at a regional level. In Italy, the region with the highest prevalence of acquired immune deficiency syndrome (AIDS) cases is Lombardy, so this disease has a high impact on the regional health care budget. ${ }^{8}$ As recently published by our working group, ${ }^{9}$ the mean total cost per year to provide health care for HIV-positive patients in the Lombardy region was stable during the period 2004-2007. However, in more recent years, several conditions have changed. New guidelines have been published recommending active treatment of chronic HCV infection in HIV-infected subjects. ${ }^{5}$ As a result, the use of drugs such as PEGylated interferon and ribavirin is expected to increase the costs of HIV care. Moreover, expensive newer drugs for HIV, such as raltegravir, darunavir, etravirine, and maraviroc, have been licensed since 2006 in Italy, and are expected to be used in the near future.

Will these elements lead to a further increase in resources consumed in the care of HIV infection? The present study aimed at answering this question, updating information on the economic burden posed by HIV-positive patients within the Lombardy regional health care system (RHS), as published by Rizzardini et al, ${ }^{9}$ with a new analysis that considered a 3-year time horizon, ie, 2007-2009.

\section{Materials and methods}

This study was a retrospective, observational, budget impact analysis, using a patient-based approach, and performed from the payer's perspective, ie, that of the RHS. Inclusion criteria were age $\geq 18$ years, confirmed HIV infection, residence in the Lombardy region, and being followed at the First Infectious Disease Department of "L Sacco" Hospital in Milan during the 3-year observation period (2007-2009), with at least one laboratory examination (CD4+ cell count and viral load) per year during the whole study period. Patients were excluded if clinical data (nonattendance at the center for more than 12 months) or cost information (patients not resident in Lombardy) were missing.

The general characteristics of each patient were recorded (gender, age, ethnicity, risk factors for HIV acquisition) as well as clinical information, ie, highest viral load and lowest CD4+ cell count in each year, CDC stage if available, antiretroviral treatment history, and $\mathrm{HCV}$ and/or hepatitis $\mathrm{B}$ virus coinfection. If the patient was not treatment-naïve, the date of first antiretroviral treatment initiation was recorded. These data were collected from the medical records of the First Infectious Disease Department at "L Sacco" Hospital. One-time general consent to the use of data was signed by the patients at their first visit to the Department for HIV infection. All data were processed and analyzed anonymously.

The perspective assumed was that of the payer which, for the purposes of the Italian National Healthcare Service, is the RHS. We were able to perform a patient-based analysis, because cost data were collected from the integrated patient database for the Lombardy region. This data warehouse contains three main databases (outpatient activity, pharmaceuticals, and inpatient activity) in which all health care services provided to each patient by any hospital or clinic (public or accredited private) participating in the RHS are recorded. The RHS provided reimbursement for outpatient procedures (visits, laboratory, and instrumented examinations), hospital admissions, HAART, and non-HAART drugs to each regional health care structure. Therefore, the data collected are the real costs incurred by the RHS, ie, the bill paid to the providers (both public and private) by the RHS for services delivered to each patient.

Data related to non-HAART drugs include all drugs prescribed for the patient and collected by any provider within the Lombardy region, including hospitals and pharmacies.

These data were provided for the study period and anonymously linked to the corresponding clinical and demographic data through a univocal code. All economic data 
collected referred to the year in which they occurred. The costs were then discounted ${ }^{10}$ at the 2009 level, taking into account the inflation rates ${ }^{11}$ of average consumer prices.

The cost analysis was performed considering both evolution of the total cost and the cost related to each service category between 2007 and 2009. Clinical data were then analyzed to identify patient characteristics that may be related to costs in each year, ie, gender, age group $(<36,36-50,>50)$, risk factor for HIV acquisition (sexual contact versus intravenous drug use), CD4+ cell count $(<200$, $200-499, \geq 500$ cells $\left./ \mathrm{mm}^{3}\right)$, detectable or undetectable viral load, HCV coinfection, and year of HAART initiation (before 1997, 1997-2003, after 2003).

Cost data were compared using the Mann-Whitney $U$ test or the Kruskal-Wallis test, respectively, for two-group and three or more group comparisons. To include all significant variables affecting the costs of care in the univariate analysis, a generalized linear model with a log link and a gamma distribution was used, as recommended for heavily skewed or tailed data. ${ }^{12,13}$ All analyses were performed using SAS for Windows version 9.1 (SAS Institute Inc, Cary, NC).

\section{Results}

The overall study sample included 483 patients (Table 1). In total, 355 subjects were male $(73.5 \%)$ and 128 were female (26.5\%). The prevalent ethnicity was Caucasian (459 patients, $95.0 \%$ ), and the mean age at study entry was $44.1 \pm 9.1$ years. The mean CD4+ cell count increased over the study period from $462 \pm 242$ cells $/ \mathrm{mm}^{3}$ in 2007 , to $513 \pm 267 \mathrm{cells} / \mathrm{mm}^{3}$ in 2008 , and to $547 \pm 262$ cells $/ \mathrm{mm}^{3}$ in 2009 . One hundred and sixty-two subjects (33.5\%) were coinfected with $\mathrm{HCV}$, and $141(29.2 \%)$ had former or current intravenous drug use as a risk factor for acquisition of HIV. The frequency of hospital admission increased slightly from 2007 to 2009 (17.4\% and $21.3 \%$, respectively), but the increase was not statistically significant. Two hundred and thirty-one patients (47.8\%) received their first antiretroviral treatment between 1997 and 2003, 128 (26.5\%) in 2004-2008, and $16(3.3 \%)$ were still naïve in 2009. Fifty-eight (12.0\%) were enrolled in the study while still naïve, and received their first antiretroviral treatment in $2007(\mathrm{n}=24), 2008(\mathrm{n}=13)$, or $2009(\mathrm{n}=5)$.

With regard to immunological status, the proportion of patients with a CD $4+$ cell count $<200$ cells $/ \mathrm{mm}^{3}$ was $12.8 \%$ in $2007,7.3 \%$ in 2008 , and $6.0 \%$ in 2009 ; considering only patients on HAART treatment, an undetectable viral load $\left(<50\right.$ copies $\left./ \mathrm{mm}^{3}\right)$ was found in $68.0 \%, 69.7 \%$, and $81.6 \%$ of patients, respectively.
Table I Baseline demographic and clinical characteristics $(n=483)$

\begin{tabular}{|c|c|c|}
\hline & \multicolumn{2}{|l|}{ Total } \\
\hline & n or mean & $\%$ or SD \\
\hline Age at study entry (years) & 44.1 & 9.1 \\
\hline \multicolumn{3}{|l|}{ Gender } \\
\hline M & 355 & $73.5 \%$ \\
\hline $\mathrm{F}$ & 128 & $26.5 \%$ \\
\hline \multicolumn{3}{|l|}{ Risk factor for HIV acquisition } \\
\hline Homosexual & 125 & $25.9 \%$ \\
\hline Heterosexual & 194 & $40.2 \%$ \\
\hline IVDU & $|4|$ & $29.2 \%$ \\
\hline Other* & 23 & $4.8 \%$ \\
\hline \multicolumn{3}{|l|}{ HCV coinfection } \\
\hline Positive & 162 & $33.5 \%$ \\
\hline Negative & 321 & $66.5 \%$ \\
\hline \multicolumn{3}{|l|}{ CD4+ cell count (cells/mm³) } \\
\hline 2007 & 462 & 242 \\
\hline 2008 & 513 & 267 \\
\hline 2009 & 547 & 262 \\
\hline \multicolumn{3}{|l|}{ CD $4+$ cell count $<200$ cell $/ \mathrm{mm}^{3}$} \\
\hline 2007 & 62 & $12.8 \%$ \\
\hline 2008 & 35 & $7.3 \%$ \\
\hline 2009 & 29 & $6.0 \%$ \\
\hline \multicolumn{3}{|l|}{ Undetectable viral load ${ }^{\S}\left(<50\right.$ copies $\left./ \mathrm{mm}^{3}\right)$} \\
\hline 2007 & 289 & $68.0 \%$ \\
\hline 2008 & 313 & $69.7 \%$ \\
\hline 2009 & 377 & $81.6 \%$ \\
\hline \multicolumn{3}{|l|}{ Viral load (log copies $/ \mathrm{mm}^{3}$ ) } \\
\hline 2007 & 3.55 & 1.25 \\
\hline 2008 & 2.54 & 1.16 \\
\hline 2009 & 2.89 & 1.02 \\
\hline \multicolumn{3}{|l|}{ Admitted patients } \\
\hline 2007 & 84 & $17.4 \%$ \\
\hline 2008 & 96 & $19.9 \%$ \\
\hline 2009 & 103 & $21.3 \%$ \\
\hline \multicolumn{3}{|l|}{ ART initiation } \\
\hline $1988-1996$ & 108 & $22.4 \%$ \\
\hline $1997-2003$ & 231 & $47.8 \%$ \\
\hline 2004-2008 & 128 & $26.5 \%$ \\
\hline Naïve in 2009 & 16 & $3.3 \%$ \\
\hline \multicolumn{3}{|l|}{ HAART regimen in 2009} \\
\hline Naïve & 16 & $3.3 \%$ \\
\hline NRTI alone & 58 & $12.0 \%$ \\
\hline NRTI + NNRTI & 127 & $26.7 \%$ \\
\hline $\mathrm{NRTI}+\mathrm{PI}$ & 220 & $45.6 \%$ \\
\hline $\mathrm{PI}+\mathrm{NNRTI}$ & 13 & $2.7 \%$ \\
\hline NRTI-sparing & 20 & $4.1 \%$ \\
\hline NRTI + raltegravir & 15 & $3.2 \%$ \\
\hline Structured treatment interruption & 14 & $3.0 \%$ \\
\hline DRV or RAL or MRV or ETV in 2009 & 54 & $11.2 \%$ \\
\hline
\end{tabular}

Notes: *Blood transfusion, vertical transmission, unknown; \&only patients on treatment.

Abbreviations: ART, antiretroviral therapy; HAART, highly active antiretroviral therapy; IVDU, intravenous drug use; NRTI, nuclease reverse transcriptase inhibitor; $\mathrm{PI}$, protease inhibitor; NNRTI, non-nuclease reverse transcriptase inhibitor; RAL, raltegravir; DRV, darunavir; ETV, etravirine; MRV, maraviroc; $H C V$, hepatitis $C$ virus; HIV, human immunodeficiency virus; SD, standard deviation. 
New drugs (raltegravir, darunavir, etravirine, maraviroc) licensed and reimbursed by the RHS after 2006 were scarcely used in the first year of observation (four patients, $0.9 \%$ ), but were prescribed to $54(11.2 \%)$ in 2009. Patients who were given raltegravir, darunavir, etravirine, or maraviroc had a longer duration of antiretroviral treatment than other patients (mean 10.0 versus 7.9 years, $P=0.0008$; median 11.0 and 8.0 years, respectively, $P=0.0007$ ). The mean yearly treatment costs per patient are reported in Table 2. The total cost increased by $5 \%$ in 2008 and by $25 \%$ in 2009.

In absolute terms, costs of hospitalization and HAART increased from 2007 to 2009, whereas costs for outpatient visits and non-HAART drugs decreased slightly over time. The total cost increase was significant, limiting the analyses, in turn, to experienced patients, HCV-negative patients, and HCV-negative experienced patients.

Patients on raltegravir, darunavir, etravirine, or maraviroc had significantly higher mean HAART costs $(€ 14,203.24$ versus $€ 7749.46, P<0.0001)$ as well as total costs ( $€ 18,488.73$ versus $€ 11,106.30, P<0.0001$ ) in comparison with treated patients not prescribed new drugs in 2009. The management of these patients was also more expensive in 2007 before new drug initiation ( $€ 11,550.50$ versus $€ 8754.36$, $P=0.003$ on univariate analysis).

In the univariate analysis, costs were related to age, risk factors for acquisition of HIV (sexual activity versus intravenous drug use), HCV coinfection, CD4+ cell count, viral load, and year of initiation of antiretroviral treatment, for each study year considered. Including all these variables in the multivariate model, the CD4+ count and year of antiretroviral treatment initiation remained significantly and consistently associated with costs for each study year considered (Table 3 ). Because of the close relationship between intravenous drug use as a risk factor for acquisition of HIV and HCV coinfection (94\% of intravenous drug users were also HCV-positive), two different multivariate models were applied, with consistent results, including $\mathrm{HCV}$ coinfection or risk factors. Analysis of HCV coinfection was adjusted for intravenous drug use ( $22 \%$ of HCV-positive subjects were not intravenous drug users), but not the opposite. Risk factors for acquisition of HIV, HCV coinfection, and HIV-RNA levels only occasionally showed a significant association with total costs. Whereas a detectable HIV-RNA level was associated with a lower total cost in 2007, this difference was not observed in the following years.

\section{Discussion}

The main finding of this study was an increase in HIV health care costs in this sample of patients observed between 2007 and 2009. This was due to the increase in HAART costs, which was not balanced by a decrease in other item costs, even if outpatient visits and non-HAART drug costs diminished during the study period. Another finding was a marked improvement in immunological profile and virological control that was achieved during the study period.

This study has some limitations. Firstly, the methods used to achieve the main objective do not imply estimation of indirect RHS costs, such as the cost to maintain the regional patient database. As a result, the overall cost of patient management might be higher. Secondly, the sample cannot be considered representative of all patients treated within the RHS, because clinical data were collected from only one clinical center, even if they were similar to the Italian HIV population with regard to age, gender distribution, and risks for HIV acquisition. ${ }^{8,14}$ For this reason, any inference is to be made in strictly comparative terms. Thirdly, differences among systems of reimbursement and tariffs applied by health care services worldwide affect the comparison, in terms of cost data, of the conclusions made by this study and other international evidence. Lastly, it has to be borne in mind that HAART therapies, in Italy, may be delivered only within hospitals; the RHS reimburses providers with the same amount they paid, and this amount is generally lower than the market value, as reported in previous international studies. ${ }^{15}$

The patient-based approach represented the main methodological and general strength of this analysis: direct collection of cost data from the administrative information flow and regional data warehouse allowed the clinical characteristics of patients to be related with the real costs incurred by the RHS. This was the only tool that allowed complete assessment of total costs in the clinical pathway of the HIVinfected patient.

Consistent with earlier studies, higher costs were associated with a low CD4+ cell count. ${ }^{16-21}$ Among other clinical characteristics, HCV coinfection, one of the most clinically relevant comorbidities in the HIV population, affected onethird of individuals included in the study sample. It was considered of great importance to evaluate the potential impact of $\mathrm{HCV}$ coinfection, particularly in the case of a negative interaction between infections and their therapies. In this study, it was found that being HCV-positive was related to higher costs in the whole study period, but this difference 


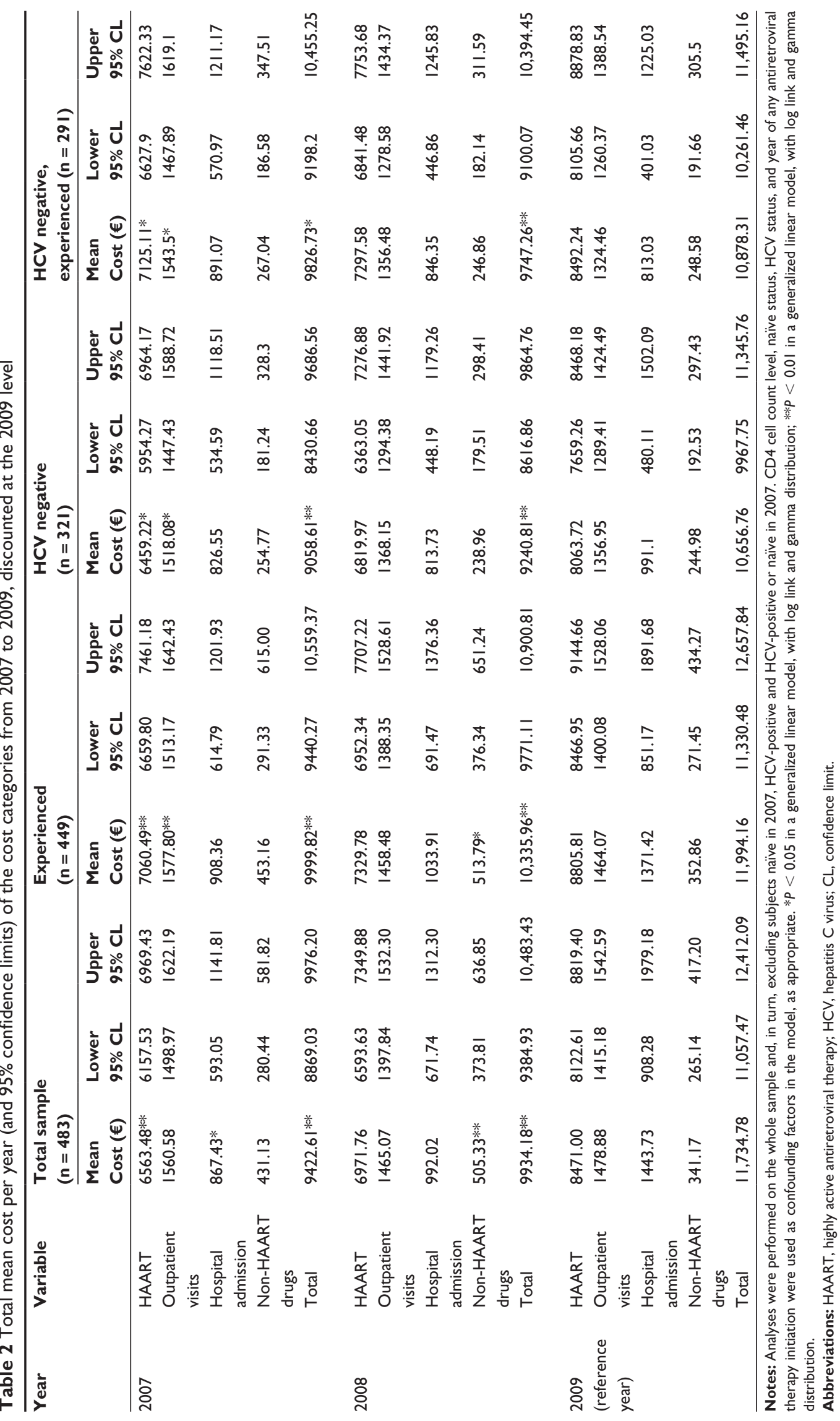


Table 3 Mean costs $(€)$ according to demographic and clinical characteristics in 2007-2009

\begin{tabular}{|c|c|c|c|c|c|c|c|c|c|c|}
\hline \multirow[t]{2}{*}{ Year } & \multirow[t]{2}{*}{ Variable } & \multicolumn{2}{|l|}{ Gender } & \multicolumn{2}{|c|}{$\begin{array}{l}\text { Risk factors for } \\
\text { HIV acquisition }\end{array}$} & \multicolumn{3}{|c|}{ Age (years) } & \multicolumn{2}{|c|}{ HCV coinfection } \\
\hline & & $\mathbf{F}$ & $\mathbf{M}$ & Sexual & IVDU & $<36$ & $36-50$ & $>\mathbf{5 0}$ & Neg & Pos \\
\hline \multirow[t]{7}{*}{2007} & HAART & 6623.68 & 6202.35 & 5956.47 & 7199.26 & 4820.95 & 6608.85 & 6067.4 & 6086.52 & 6700.17 \\
\hline & Non-HAART drugs & 273.81 & 466.8 & 217.81 & 900.29 & 49.87 & 500.49 & 403.96 & 272.59 & 681.88 \\
\hline & Outpatient visits & 1605.78 & I463.34 & | 468.98 & 1605.79 & 1404.28 & 1480.24 & 1615.87 & 1469.58 & 1580.89 \\
\hline & Hospital admission & 835.55 & 834.37 & 715.12 & II09.01 & 901.77 & 774.34 & 1037.36 & 809.44 & 913.99 \\
\hline & Total & 9338.82 & 8966.85 & 8358.38 & $108 \mid 4.4$ & 7176.87 & 9363.92 & 9124.6 & 8638.14 & 9876.94 \\
\hline & Discounted at 2009 level & 9705.13 & 9318.57 & 8686.23 & $11,238.5$ & 7458.38 & 9731.21 & 9482.5 & 8976.96 & $10,264.4$ \\
\hline & $p^{*}$ & 0.56 & & 0.04 & & 0.77 & & & 0.12 & \\
\hline \multirow[t]{7}{*}{2008} & HAART & 7346.18 & 6767.56 & 6765.37 & 7300.68 & 5867.17 & 7155.27 & 6710.76 & 6735.26 & 7287.26 \\
\hline & Non-HAART drugs & 477.78 & 510.67 & 372.33 & 850.55 & 276.91 & 586.62 & $4 \mid 2.72$ & 243.54 & 973.77 \\
\hline & Outpatient visits & 1619.8 & 1394.15 & $|4| 4.3$ & 1580.32 & 1309.12 & | 489.87 & 1417.46 & 1341.47 & 1661.22 \\
\hline & Hospital admission & 1037.67 & 965.77 & 708.51 & 1659.91 & 556.16 & 890.64 & 1766.53 & 850.76 & 1275.38 \\
\hline & Total & $10,48 \mid .4$ & 9638.15 & 9260.51 & II,39|.5 & 8009.35 & $10,122.4$ & $10,307.5$ & 9171.03 & $11,197.6$ \\
\hline & Discounted at 2009 level & $10,554.8$ & 9705.62 & 9325.33 & II,47|.2 & 8065.42 & $10,193.3$ & $10,379.6$ & 9235.23 & 11276 \\
\hline & $P^{*}$ & 0.53 & & 0.62 & & 0.78 & & & 0.10 & \\
\hline \multirow[t]{6}{*}{2009} & HAART & 8787.35 & 8354.5 & 8023.89 & 9417.42 & 6890.15 & 8796.53 & 8311.38 & 8047.2 & 9236.91 \\
\hline & Non-HAART drugs & 283.73 & 362.32 & 257.36 & 560.51 & 73.89 & 372.86 & 449.62 & 235.44 & 539.58 \\
\hline & Outpatient visits & 1641.12 & 1419.14 & $|4| 5.74$ & 1661.67 & 1203.25 & 1500.5 & 1546.3 & 1345.17 & $|707.7|$ \\
\hline & Hospital admission & 1434.78 & I 447.03 & 1034.64 & 2494.55 & 447.01 & 1309.56 & 2569.58 & 975.09 & 2323.28 \\
\hline & Total 2009 & 12,147 & 11,583 & $10,731.6$ & $|4| ,34 . \mid$ & $86 \mid 4.3$ & II,979.5 & $12,876.9$ & $10,602.9$ & $13,807.5$ \\
\hline & P* & 0.13 & & 0.31 & & 0.14 & & & 0.03 & \\
\hline
\end{tabular}

Note: *Multivariate analysis including gender, age group, risk factor for HIV acquisition, HCV coinfection, CD4 cell count and HIV RNA in the calendar year, year of ART initiation.

Abbreviations: ART, antiretroviral therapy; HAART, highly active antiretroviral therapy; HIV, human immunodeficiency virus; HCV, hepatitis C virus; IVDU, intravenous drug use.

achieved statistical significance only in 2009. This increase may be due in part to the new guidelines ${ }^{5}$ indicating that HCV-coinfected subjects should be treated when HCV-RNA is detectable. Since 2008, an agreement with the Lombardy region allowed hospitals to purchase ribavirin and PEGylated interferon directly and provide these drugs to patients. Their costs were recorded in the same database as HAART, so their economic burden could not be differentiated from that of HAART. Therefore, an increase due to these drugs is probable, as well as a decrease in the mean non-HAART drug cost (before 2008 ribavirin and PEGylated interferons were included in this category). However, limiting the analysis to HCV-negative patients, there was still a higher HAART cost in 2009 compared with 2007 . The 2009 total cost was also higher than 2007 and 2008 total costs.

Another reason why there was an increase in costs is that expensive newer drugs have been licensed in recent years. In our study sample, whilst only four patients were on raltegravir, darunavir, etravirine, or maraviroc in 2007, 54 subjects were on treatment with at least one of these agents in 2009. In comparison with other antiretroviral drugs, the HAART cost for these treatments was almost doubled, resulting in a higher mean total cost. However, recently licensed drugs were mainly prescribed to multi-experienced patients without other therapeutic options. In patients with a longer history of antiretroviral treatment, new drugs presumably contributed to maintain or improve their immunological status, and are a strong determinant of future costs and an important predictor of opportunistic infections and death. ${ }^{22}$

The increase in HAART costs may also be due to patients switching to more expensive drugs than raltegravir, darunavir, etravirine, and maraviroc. On the other hand, the costs of older drugs remained stable or decreased slightly from 2007 to 2009, so patients remaining on the same regimen over the study period did not contribute to the increased cost of HAART. The cost increase was also partially due to 42 HAART-naïve patients being started on therapy. However, when the analysis was limited to experienced patients, the cost increase still occurred.

Finally, the cost increase may also be due to age-related rather than HIV-related issues, taking into account the fact that the study population was ageing during the observation period. This was suggested in a recent Italian study ${ }^{23}$ concluding that the cost to the National Healthcare Service of people living with HIV is likely to increase as a result of prolonged survival, ageing, and an increased risk of other chronic diseases.

A previous study conducted by the present investigators ${ }^{9}$ concluded that the total cost of providing health care services to HIV-positive patients in the Lombardy region was stable 


\begin{tabular}{|c|c|c|c|c|c|c|c|c|c|}
\hline \multicolumn{3}{|c|}{ CD4 cell count $/ \mathrm{mm}^{3}$} & \multicolumn{2}{|c|}{ HIV RNA } & \multicolumn{3}{|c|}{ Year of ART initiation } & \multicolumn{2}{|c|}{ New drugs in 2009} \\
\hline$<200$ & $200-499$ & $>\mathbf{5 0 0}$ & Undet & Det & $\geq 1996$ & $1997-2003$ & $\geq 2004$ & No & Yes \\
\hline 7249.49 & 6269.46 & 6075.94 & 7327.74 & 5835.96 & 7861.22 & 6255.38 & 5910.17 & 6109.46 & 7954.60 \\
\hline 710.52 & 499 & 205.84 & 468.72 & 361.09 & 844.01 & 306.18 & 289.42 & |449.28 & 1917.95 \\
\hline 1823.05 & 1564.92 & $|3| 1.6 \mid$ & $14 \mid 0.79$ & 1727.89 & 1634.53 & 1430.29 & 1543.85 & 780.48 & $|265.3|$ \\
\hline 2092.21 & 753.01 & 503.24 & 689.24 & II82.08 & 1090.83 & 723.15 & 884.2 & 415.14 & $4 \mid 2.63$ \\
\hline II,875.3 & 9086.39 & 8096.62 & 9896.49 & 9107.02 & $11,430.6$ & $87 \mid 4.99$ & 8627.64 & 8754.36 & $\mathrm{II}, 550.50$ \\
\hline$|2,34| . \mid$ & 9442.79 & 8414.2 & $10,284.7$ & 9464.23 & 11879 & 9056.83 & 8966.05 & 9097.46 & $12,003.55$ \\
\hline$<0.000$ I & & & 0.04 & & $<0.000$ I & & & 0.08 & \\
\hline 8401.39 & 6820.02 & 6794.94 & 7455.54 & 6888.83 & 8122.06 & 6707.52 & 7166.65 & 6597.03 & 9515.29 \\
\hline II 80.27 & 585.82 & 304.27 & 464.76 & 589.48 & 692.74 & 534.67 & 271.2 & |430.1 I & $|65| .7 \mid$ \\
\hline 1817.56 & $|56| .3 \mid$ & 1284.38 & | 388.85 & 1613.53 & I582.74 & 1399.48 & | 464.74 & 851.69 & 2045.22 \\
\hline 2261.31 & II72.I & 582.97 & 800.12 & I 446.62 & 1914.03 & 754.87 & 721.04 & 511.68 & 423.46 \\
\hline $13,660.5$ & $10,139.3$ & 8966.55 & $10,109.3$ & $10,538.5$ & $|2,3| \mid .6$ & 9396.55 & 9623.63 & $9390.5 \mathrm{I}$ & $13,635.68$ \\
\hline $13,756.2$ & $10,210.2$ & 9029.32 & 10180 & $10,6 \mid 2.2$ & $12,397.8$ & 9462.33 & 9691 & 9456.24 & $|3,73| . \mid 3$ \\
\hline 0.0005 & & & 0.34 & & $<0.0001$ & & & 0.001 & \\
\hline 8988.13 & 8558.7 & 8332.21 & 9067.6 & 7636.83 & 10.129 & 8216.52 & 8506.64 & 7749.46 & | 4.203 .24 \\
\hline 463.44 & 385.5 & 287.68 & 347.29 & 361.79 & 395.81 & 362.28 & 285.65 & 1454.08 & 1675.93 \\
\hline 1661.6 & I595.84 & 1354.53 & |465.26 & 1462.23 & 1594.08 & 1478.66 & 1385.32 & 1341.30 & 2257.48 \\
\hline 4035.9 & $|89| .03$ & 741.25 & 1101.78 & 2478.82 & 1802.83 & 1551.22 & 1029.22 & 339.79 & 352.09 \\
\hline $15,|49|$. & $|2,43| . \mid$ & $10,715.7$ & $11,981.9$ & II,939.7 & $13,92 \mid .8$ & II,608.7 & II,206.8 & $10,884.64$ & I8,488.73 \\
\hline 0.0006 & & & 0.06 & & 0.046 & & & $<0.0001$ & \\
\hline
\end{tabular}

for the 2004-2007 period, with the percentage impact of HAART on the total cost increasing and other cost components diminishing from 2004 to 2007. Conversely, in the present study, there was a significant increase in the total cost for the 2007-2009 period. This increase was due to HAART and hospital admissions; the cost for concurrent drug treatments and outpatient visits showed a slight reduction, but not sufficient to balance the increase in other cost components.

In this sample, the effectiveness of HAART was shown by an increase in CD4+ cell count, which is a major predictor of costs, and a greater proportion of patients with undetectable HIV-RNA. However, the immunological improvement was achieved at a higher cost in the short term. Whether this increase will be compensated for by a long-term decrease in opportunistic infections and management costs of HIVrelated events is an area still to be investigated.

\section{Acknowledgment}

The authors thank the Health General Directorate of the Lombardy region for providing the cost data in anonymous form.

\section{Disclosure}

The authors report no conflict of interest in this work.

\section{References}

1. Porter K, Babiker A, Bhaskaran K, et al. CASCADE Collaboration. Determinants of survival following HIV-1 seroconversion after the introduction of HAART. Lancet. 2003;362:1267-1274.

2. Walensky RP, Paltiel AD, Losina E, et al. The survival benefits of AIDS treatment in the United States. J Infect Dis. 2006;194:1-5.

3. Salute.org.it. Italian Ministry of Health. Linee Guida Italiane sull'utilizzo dei farmaci antiretrovirali e sulla gestione diagnostico-clinica delle persone con infezione da HIV-1. Ottobre, 2011. http://www.salute.gov.it/ imgs/C_17_pubblicazioni_1301_allegato.pdf. Accessed April 10, 2012.

4. EuropeanAIDSClinicalSociety.org. EACS - European AIDS Clinical Society Guidelines. October, 2011. http://www.europeanaidsclinicalsociety.org/images/stories/EACS-Pdf/eacsguidelines-v6_english.pdf. Accessed April 10, 2012.

5. AIDSinfo.nih.gov. DHHS Panel on Antiretroviral Guidelines for Adults and Adolescents. Guidelines for the use of antiretroviral agents in HIV-1-infected adults and adolescents. January 29, 2008. http://www. aidsinfo.nih.gov/ContentFiles/AdultandAdolescentGL.pdf. Accessed April 10, 2012.

6. Sanita.Regione.Lombardia.it. Giunta Regionale Lombardia. Determinazione in ordine alla gestione del servizio socio sanitario regionale per l'esercizio 2012. DRG IX/2633 HYPERLINK “http://www.sanita. regione.lombardia.it/cs/Satellite" www.sanita.regione.lombardia.it/cs/ Satellite. Accessed April 10, 2012.

7. Stoll M, Kollan C, Bergmann F, et al. Calculation of direct antiretroviral costs and potential cost savings by using generics in the German HIV ClinSurv Cohort. PlosOne. 2011;6:e23946.

8. ISS:it. Istituto Superiore di Sanità. Aggiornamento delle nuove diagnosi di infezione da HIV e dei casi di AIDS in Italia, http://www.iss.it/binary/ pres/cont/dic2008.1228391047.pdf. Accessed April 10, 2012.

9. Rizzardini G, Restelli U, Porazzi E, et al. The cost of HIV disease in Northern Italy: the payer's perspective. J Acquir Immune Defic Syndr. 2011;57:211-217. 
10. Drummond FM, Sculpher MJ, Torrance GW, O’Brien BJ, Stoddart GL. Methods for the Economic Evaluation of Health Care Programmes. Cary, NC: Oxford University Press; 2005.

11. IMF.org. International Monetary Fund. World Economic Outlook Database, April 2010. http://www.imf.org/external/pubs/ft/weo/2010/01/ weodata/weorept.aspx? $\mathrm{sy}=2000 \&$ ey $=2010 \& \mathrm{scsm}=1 \& \mathrm{ssd}=1 \&$ sort $=\mathrm{c}$ ountry $\& d s=. \& b r=1 \& c=136 \& s=$ PCPI $\% 2$ CPCPIPCH $\% 2$ CPCPIE $\% 2$ CPCPIEPCH\&grp $=0 \& \mathrm{a}=\& p r 1 . \mathrm{x}=58 \& \operatorname{pr} 1 . \mathrm{y}=14$. Accessed April 10, 2012.

12. Buntin MB, Zaslavsky AM. Too much ado about two-part models and transformation? Comparing methods of modeling Medicare Expenditures. J Health Econ. 2004;23:525-542.

13. Blough DK, Madden CW, Hornbrook MC. Modeling risk using generalized linear models. J Health Econ. 1999;18:153-171.

14. POSIT. La persona con infezione da HIV in Italia. Rilevazione 2007-2008-2009. HYPERLINK “http://www.posit-nadir.org/posit/ ProfiloGenerale.aspx” www.posit-nadir.org/posit/ProfiloGenerale.aspx. Accessed April 10, 2012.

15. Schackman BR, Gebo KA, Walensky RP, et al. The lifetime cost of current human immunodeficiency virus care in the United States. Med Care. 2006;44:990-997.

16. Hill A, Gebo K. Predicting HIV care cost using CD4+ counts from clinical trials. Am J Manag Care. 2007;13:524-528.
17. Gebo KA, Fleishman JA, Conviser R, et al. Contemporary costs of HIV healthcare in the HAART era. AIDS. 2010;24:2705-2715.

18. Krentz HB, Gill MJ. Cost of medical care for HIV infected patients within a regional population from 1997 to 2006. HIV Med. 2008;9: $721-730$.

19. Krentz HB, Auld MC, Gill MJ. The high cost of medical care for patients who present late $(\mathrm{CD} 4+<200$ cells/ $\mu \mathrm{l})$ with HIV infection. HIV Med. 2004;5:93-98.

20. Krentz HB, Gill J. Despite CD4+ cell count rebound the higher initial cost of medical care for HIV infected patients persist 5 years after presentation with CD4+ cell counts less than $350 \mu 1$. AIDS. 2010;24: 2750-2753.

21. Garattini L, Tediosi F, Di Cinto E, et al. Resource utilization and hospital cost of HIV/AIDS care in Italy in the era of highly active antiretroviral therapy. AIDS Care. 2001;13:6733-6741.

22. Cockerham L, Scherzer R, Zolopa A, et al. Association of HIV infection, demographic and cardiovascular risk factors with all-cause mortality in the recent HAART era. J Acquir Immune Defic Syndr. 2010;53:102-106.

23. Magoni M, Scarcella C, Vassallo F, et al. The evolving burden of HIV infection compared with other chronic diseases in northern Italy. HIV Med. 2011;12:129-137.
ClinicoEconomics and Outcomes Research

\section{Publish your work in this journal}

ClinicoEconomics \& Outcomes Research is an international, peerreviewed open-access journal focusing on Health Technology Assessment, Pharmacoeconomics and Outcomes Research in the areas of diagnosis, medical devices, and clinical, surgical and pharmacological intervention. The economic impact of health policy and health systems

\section{Dovepress}

organization also constitute important areas of coverage. The manuscript management system is completely online and includes a very quick and fair peer-review system, which is all easy to use. Visit http://www.dovepress.com/testimonials.php to read real quotes from published authors. 